\title{
Ammonium Bisphosphonate Polymeric Magnetic Nanocomplexes for Platinum Anticancer Drug Delivery and Imaging with Potential Hyperthermia and Temperature-Dependent Drug Release
}

\author{
Rui Zhang $\mathbb{D}^{1},{ }^{1}$ Benjamin Fellows, ${ }^{2}$ Nikorn Pothayee $\mathbb{D}^{\mathbb{D}},{ }^{3}$ Nan $\mathrm{Hu},{ }^{1}$ Nipon Pothayee, ${ }^{1}$ Ami Jo, \\ Ana C. Bohórquez, ${ }^{4}$ Carlos Rinaldi, ${ }^{4}$ Olin Thompson Mefford, ${ }^{2}$ Richey M. Davis, ${ }^{1}$ \\ and Judy S. Riffle ${ }^{1}{ }^{1}$ \\ ${ }^{1}$ Department of Chemistry, Department of Chemical Engineering, and Macromolecules Innovation Institute, Virginia Tech, \\ Blacksburg, VA 24061, USA \\ ${ }^{2}$ Department of Materials Science and Engineering and the Center for Optical Materials Science and Engineering (COMSET), \\ Clemson University, Clemson, SC 29634, USA \\ ${ }^{3}$ Laboratory of Functional and Molecular Imaging, National Institute of Neurological Disorders and Stroke, National Institutes \\ of Health, Bethesda, MD 20892, USA \\ ${ }^{4}$ J. Crayton Pruitt Family Department of Biomedical Engineering and Department of Chemical Engineering, University of Florida, \\ Gainesville, FL 32611, USA
}

Correspondence should be addressed to Nikorn Pothayee; nikorn.pothayee@nih.gov and Judy S. Riffle; jriffle@vt.edu

Received 29 March 2018; Revised 4 June 2018; Accepted 11 June 2018; Published 5 August 2018

Academic Editor: Ana Espinosa

Copyright ( $) 2018$ Rui Zhang et al. This is an open access article distributed under the Creative Commons Attribution License, which permits unrestricted use, distribution, and reproduction in any medium, provided the original work is properly cited.

Novel magnetite-ammonium bisphosphonate graft ionic copolymer nanocomplexes (MGICs) have been developed for potential drug delivery, magnetic resonance imaging, and hyperthermia applications. The complexes displayed relatively uniform sizes with narrow size distributions upon self-assembly in aqueous media, and their sizes were stable under simulated physiological conditions for at least 7 days. The anticancer drugs, cisplatin and carboplatin, were loaded into the complexes, and sustained release of both drugs was observed. The transverse NMR relaxivities $\left(r_{2} \mathrm{~s}\right)$ of the complexes were $244 \mathrm{~s}^{-1}(\mathrm{mM} \mathrm{Fe})^{-1}$ which is fast compared to either the commercial $\mathrm{T}_{2}$-weighted MRI agent Feridex IV ${ }^{\circledR}$ or our previously reported magnetite-block ionomer complexes. Phantom MRI images of the complexes demonstrated excellent negative contrast effects of such complexes. Thus, the bisphosphonate-bearing MGICs could be promising candidates for dual drug delivery and magnetic resonance imaging. Moreover, the bisphosphonate MGICs generate heat under an alternating magnetic field of $30 \mathrm{kA} \cdot \mathrm{m}^{-1}$ at $206 \mathrm{kHz}$. The temperature of the MGIC dispersion in deionized water increased from 37 to $41^{\circ} \mathrm{C}$ after exposure to the magnetic field for 10 minutes, corresponding to a specific absorption rate of $77.0 \mathrm{~W} \cdot \mathrm{g}^{-1}$. This suggests their potential as hyperthermia treatment agents as well as the possibility of temperature-dependent drug release, making MGICs more versatile in potential drug delivery applications.

\section{Introduction}

Nanoscale drug delivery and imaging systems have received tremendous interest in the past few decades [1-12]. They enjoy some intrinsic advantages over conventional drug delivery approaches. Due to the small sizes of the nanoparticles, they can transport through capillaries and enter cells, therefore leading to higher drug accumulation at the desired site [2]. Drug release depends on the interaction between the drug and the carrier, and this can be carefully designed and fabricated. Such systems can also lead to long drug circulation times [13]. 
With the aim of improving drug bioavailability and minimizing cytotoxicity, a multitude of drug delivery systems have been developed to address the issues of drug efficacy and circulation time in the bloodstream during delivery $[14,15]$. Micellar polymeric drug carriers have been of particular interest due to the advantages of self-assembly in water and their potential for large-scale industrial production. These carriers can form core-shell micelles via self-assembly with therapeutic and diagnostic agents in water, and they can be either amphiphilic nonionic or ionic block copolymers [16-20]. They feature a water-soluble segment, and a hydrophobic segment or an ionic segment. The hydrophobic or ionic segment can be designed to bind metal or metal oxide nanoparticles and to form complexes with hydrophobic drugs. Those components form the cores of micellar complexes in water. Interactions in the core among the different components are largely noncovalent and can include electrostatic interactions, hydrophobic interactions, hydrogen bonding, and metal-ligand complexation [2]. Specifically for the block or graft ionic copolymers that contain a hydrophilic segment and an ionic segment, the interactions can combine both electrostatic and metal-ligand interactions. This leads to the formation of core-shell micellar structures with a nonionic hydrophilic shell and an ionic core that is comprised of the anionic polymer segment as well as the bound transition metals or metal oxides. The residual unbound ionic segment provides binding sites for drug loading via ionic complexation [21]. The hydrophilic segment, which is typically poly(ethylene oxide), plays the role of improving dispersibility and biocompatibility of the complexes [22].

Iron oxide nanoparticles, particularly magnetite nanoparticles (MNPs), have been reported to be a versatile and powerful probe in biomedical applications such as nanoparticle-based imaging and cancer therapy approaches [23-25]. They have been utilized as effective contrast enhancement agents for transverse $\left(\mathrm{T}_{2}\right.$-weighted) magnetic resonance imaging (MRI) due to their low toxicity and high magnetization in magnetite-polymer complexes [21]. MNPs of certain sizes can generate heat upon exposure to an alternating magnetic field (AMF), making them potentially useful for local magnetic hyperthermia therapy or for triggered drug release if drugs are encapsulated in the magnetite-based nanocarriers $[6,26]$. MNPs are usually coated with natural or synthetic biocompatible macromolecules such as dextran or poly(ethylene oxide)-containing copolymers to prevent aggregation for biomedical applications [27, 28]. This increases their colloidal stability in physiological media and minimizes toxicity [29-31]. The magnetite-ionic copolymer complexes can be used as contrast agents for MRI. Colloidally stable magnetite-copolymer complexes can also serve as carriers for selectively storing and releasing small molecules which make them potentially attractive drug carriers for cancer therapy.

Cancer is a major public health problem in the United States and worldwide [32]. It is reported to be the second leading cause of death in the United States and is approaching the rate for the current number one cause, cardiovascular/heart diseases $[33,34]$. More than $85 \%$ of cancers eventually lead to the formation of solid tumors [35]. Many therapies have been developed, aimed at blocking the biological activities of tumor cells and killing them. A family of platinum therapeutic agents is in clinical use to treat various cancer types [36]. A first-generation platinum drug, cisplatin, a second-generation drug, carboplatin, and a third-generation analog, oxaliplatin, are potent antitumor drugs which have achieved success in treating some types of malignant tumors such as testicular, lung, ovarian, and colon tumors [37-41]. However, due to their lack of selectivity and to drug resistance complications, as well as their low solubility and high cytotoxicity, especially in the case of cisplatin, their applications have been limited $[36,42]$. Nanocarrier-based delivery of platinum complexes is a therapeutic alternative that has evolved over the last decade as an approach to cancer therapy [42, 43]. Compared to low molecular weight drugs which rapidly pass through the cell membranes of both normal and cancerous tissues, drugs which are loaded into nanocarriers of certain sizes can passively accumulate into solid tumors via the enhanced permeability and retention effect, promoting drug uptake into tumor sites with reduced off-target toxicity effects [44]. In addition, nanoparticle drug delivery systems have shown improvement of the pharmacokinetic and pharmacodynamic profiles of the chemotherapeutic payloads and have promoted controlled and sustained release of platinum drugs [45-47]. Use of these nanocarriers may enable high intracellular concentration in cancer cells and achieve potential stimulus-responsive drug release, while suppressing the development of multidrug resistance [43, 48-51].

Hyperthermia has also generated research interest for biomedical applications such as cancer treatment and drug/ gene delivery [52-57]. Magnetic nanoparticles can act as a heating source via magnetically mediated hyperthermia that involves heating of specific tissues or organs to between 41 and $46^{\circ} \mathrm{C}$ [53]. When the temperature is raised to $41-43^{\circ} \mathrm{C}$, tumor cells can be irreversibly damaged while normal tissues may not be, because tumor cells are more sensitive to heat than normal cells are $[58,59]$. Since magnetic fields can penetrate human tissues, treatment by hyperthermia may serve as a noninvasive method to kill cancer cells [60]. Moreover, it has been found that hyperthermia greatly enhances treatments by radiotherapy or chemotherapy for several cell lines including those found in brain tumors [61-63]. Hyperthermia studies on rats and dogs have shown positive results as well [58]. Magnetite nanoparticles can have a high specific absorption rate (SAR) of energy, which is ideal for hyperthermia applications [64]. Utilization of iron oxide nanoparticles for magnetically induced hyperthermia has been reported to kill cancer cells, and these are in clinical trials for brain and prostate cancer patients [61, 65-67].

Phosphonic acid-containing polymers have recently triggered interest in biomedical fields, and there have been multiple reports of their potential for drug delivery [68-70]. Portet et al. studied different types of polymer coatings for iron oxide nanoparticles, which included sulfonates, phosphonates, and carboxylates [71]. The phosphonate-bearing polymer-magnetite complexes displayed much better hydrodynamic stability at pH 7.0 compared to the stability of analogous carboxylate-containing complexes. The hydrodynamic sizes of the particles remained unchanged for over two weeks. 
Mohapatra and coworkers modified the surfaces of magnetite nanoparticles with 2-carboxyethyl phosphonic acid and carboxylic acid [72]. Subsequently, the carboxylic acids were conjugated with folic acid. The sizes of the nanoparticles with and without conjugated folic acid remained unchanged over a $\mathrm{pH}$ range of 4.5-8, indicating strong binding between the magnetite and the phosphonate groups. Previously, our group $[47,73]$ prepared ammonium bis(phosphonate)-functional poly( $N$-isopropylacrylamide)-magnetite and poly(ammonium bisphosphonic acid methacrylate)-gPEO-manganese(II) nanoparticles. Both complexes were colloidally stable in phosphate-buffered saline (PBS) at $\mathrm{pH} 7.4$ for an extended period. Thus, phosphonate-containing polymers can be promising candidates for making colloidally stable nanocarriers for drug delivery.

In this paper, we report magnetite-graft ionomer complexes (MGICs) that were made by adsorbing poly(ammonium bisphosphonic acid methacrylate)-g-poly(ethylene oxide) onto magnetite. Analogous poly(acrylic acid)-bearing graft ionic copolymers were also used to make comparisons. A portion of either the bisphosphonic acid or the acrylic acid of the copolymer was complexed with the magnetite surfaces to form a core, while the poly(ethylene oxide) (PEO) component extended into water to form the shell to provide colloidal stability in aqueous solutions. Cisplatin and carboplatin were loaded into the complexes, and drug release was measured in simulated endosomal $(\mathrm{pH}=4.6)$ and physiological conditions $(\mathrm{pH}=7.4)$. Physicochemical properties, charge characteristics, and hydrodynamic stabilities were measured and compared to other previously reported systems to evaluate the potential of such nanoparticles for drug delivery. The specific absorption rate of hexyl bisphosphonate MGICs in an aqueous dispersion was measured to evaluate the potential of the complexes for heat-induced drug release and/or hyperthermia treatment. Transverse relaxivities and phantom MRI images were obtained to evaluate their potential for $\mathrm{T}_{2}$-weighted magnetic resonance imaging.

\section{Results and Discussion}

A primary research interest in our group is on developing metal oxide/ionic-copolymer nanocomplexes for potential applications such as magnetic resonance imaging and drug delivery. In this contribution, we designed magnetite nanoparticles coated with ammonium bisphosphonate graft copolymers to bind strongly to platinum-based cancer drugs via ionic interactions. This is in part because the release kinetics of platinum-based drugs from such magnetitephosphonate-containing ionic copolymer complexes and their MRI potentials have not been studied to date. By combining both phosphonate-bearing ionic graft copolymers and magnetite nanoparticles and making corresponding magnetite-copolymer complexes, a multifunctional drug delivery system that generates heat and enables potential triggered drug release by exposing them to an alternating magnetic field was created [74, 75].

2.1. Synthesis of Magnetite Nanoparticles Coated with Ammonium Bisphosphonate-PEO Graft Copolymers (MGICs).
The ammonium bisphosphonate-PEO graft copolymers reported herein were prepared by free radical copolymerization of PEO-monoacrylate macromonomers with an ammonium bisphosphonate methacrylate monomer [76]. An analogous polyacrylate-PEO graft copolymer was also prepared so that the properties of the complexes could be compared in terms of using carboxylates versus phosphonates. Magnetite nanoparticles were synthesized by thermal decomposition of an organometallic precursor as described by Park et al. with some modifications [77]. During the preparation of the magnetite-graft copolymer complexes, the phosphonate anions displaced part of the oleic acid coating on the surface of the nanoparticles to produce a core-shell particle $[78,79]$. The process required homogeneous dispersion of the ionomers and the oleic acid-coated magnetite in organic solvents so that the ionic copolymers could adsorb onto the magnetite core without significant repulsion of the anionic charges in the copolymer. The copolymers were readily soluble in $\mathrm{N}, \mathrm{N}$-dimethylformamide (DMF), while the oleic acid-coated magnetite nanoparticles were dispersible in chloroform. A mixed solvent system of $1: 1 \mathrm{v}: \mathrm{v}$ DMF: chloroform was used for the adsorption step. After the reaction, the nanoparticles were then precipitated and washed extensively with hexane and diethyl ether to remove free oleic acid, low molecular weight impurities, and any residual trioctylamine solvent derived from the magnetite formation process. The particles were first dried under a nitrogen purge at room temperature then recovered by freeze-drying to avoid nanoparticle aggregation that might occur by drying at an elevated temperature. As shown in Figure 1(a), the oleic acid-coated magnetic nanoparticles were well-dispersed as individual particles prior to the polymer coating process. Upon complexation with ammoniumbisphosphonate-PEO graft copolymers, the particles appeared to form cluster-like structures (Figure 1(b)). Indeed, the hydrodynamic sizes measured by DLS suggested that these particles were large and not likely to be individual iron oxide particles coated with copolymer.

2.2. Physicochemical Properties and Colloidal Stability of the MGICs. It was of great interest to examine whether the bisphosphonate-containing and the acrylate-bearing graft copolymers would bind to magnetite with conspicuous differences in terms of physicochemical properties, charge characteristics, and hydrodynamic stabilities. A previous study by our group utilizing similar graft copolymers to complex with manganese(II) indicated that the bisphosphonate graft copolymers bound more strongly to manganese than the carboxylate copolymer [47]. Table 1 lists the intensity average diameters, polydispersity indices, and zeta potentials of the graft copolymer-magnetite complexes and drugloaded MGICs. All of the complexes had low polydispersity indices (PDIs) as measured by DLS, which indicated that the sizes of these nanocomplexes were relatively uniform in hydrodynamic diameters without noticeable aggregation/ agglomeration. This eliminated any concern that the MGICs (i.e., with graft copolymers) would not form complexes with desirable sizes and PDIs that were as uniform as with block copolymers made in controlled free radical polymerizations. 


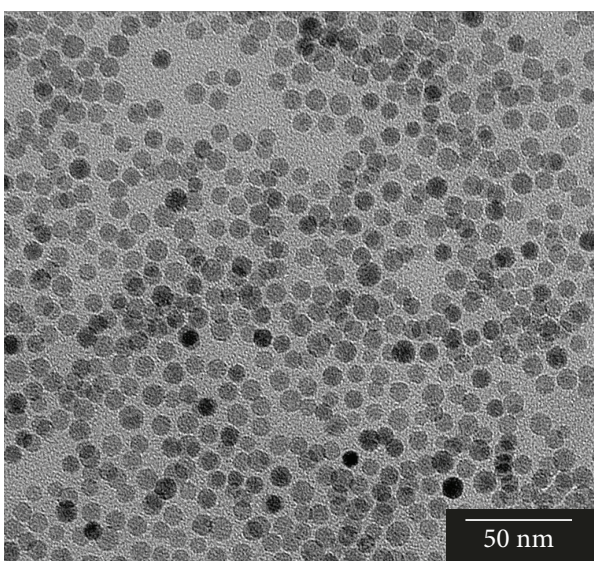

(a)

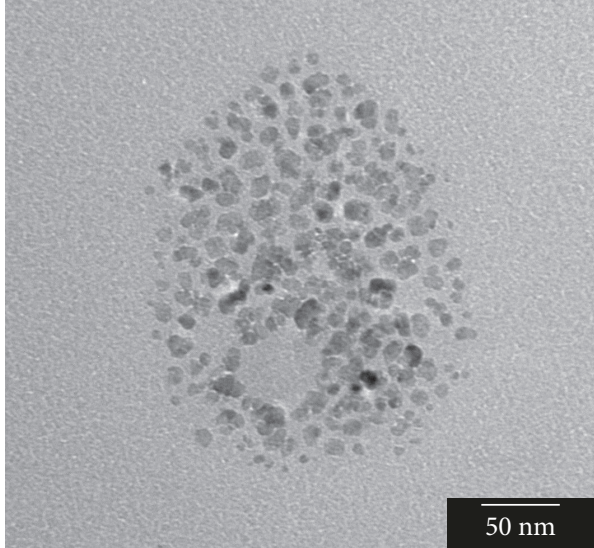

(b)

FIGURE 1: TEM micrograph of the oleic-acid coated magnetite nanoparticles (a) and MGICs (b).

TABLE 1: The intensity average diameters, polydispersity indices, and zeta potentials of MGICs and magnetite-block ionomer complexes.

\begin{tabular}{|c|c|c|c|c|}
\hline Sample & Polymer coating composition & $\begin{array}{l}\text { Intensity average } \\
\text { diameter }(\mathrm{nm})\end{array}$ & PDI & $\begin{array}{l}\text { Zeta potential } \\
(\mathrm{mV})\end{array}$ \\
\hline MGIC carboxylate & PAA-g-PEO (50:50 wt:wt) & $131 \pm 3$ & 0.13 & $-56 \pm 1$ \\
\hline MGIC propyl bisphosphonate & $\begin{array}{l}\text { Poly(propyl ammonium bisphosphonic acid)- } g \text {-PEO } \\
\qquad(60: 40 \mathrm{wt}: \mathrm{wt})\end{array}$ & $100 \pm 2$ & 0.16 & $-47 \pm 1$ \\
\hline MGIC hexyl bisphosphonate & $\begin{array}{l}\text { Poly(hexyl ammonium bisphosphonic acid)- } g \text {-PEO } \\
\qquad(60: 40 \mathrm{wt}: \mathrm{wt})\end{array}$ & $105 \pm 2$ & 0.14 & $-49 \pm 1$ \\
\hline $\begin{array}{l}\text { Cisplatin-MGIC hexyl } \\
\text { bisphosphonate }\end{array}$ & $\begin{array}{l}\text { Poly(hexyl ammonium bisphosphonic acid)-g-PEO } \\
\qquad(60: 40 \mathrm{wt}: \mathrm{wt})\end{array}$ & $141 \pm 1$ & 0.15 & $-43 \pm 1$ \\
\hline $\begin{array}{l}\text { Carboplatin-MGIC hexyl } \\
\text { bisphosphonate }\end{array}$ & $\begin{array}{l}\text { Poly(hexyl ammonium bisphosphonic acid)- } g \text {-PEO } \\
\qquad(60: 40 \mathrm{wt}: \mathrm{wt})\end{array}$ & $130 \pm 1$ & 0.15 & $-44 \pm 1$ \\
\hline
\end{tabular}

The complexes were designed to incorporate an excess of anions in the magnetite-ionomer complexes, so that either residual carboxylate or phosphonate groups could provide binding sites for charged or metal-containing drugs such as doxorubicin and cisplatin. The zeta potentials of all the MGICs were strongly negative as measured by DLS, indicating that substantial amounts of anions still existed (Table 1). The relatively uniform sizes, discrete size distributions, and zeta potentials of the MGICs lead to the conclusion that ionic graft copolymers can be used to form complexes with magnetite for potential drug delivery applications. Further experiments may be needed to compare the colloidal stability between the carboxylate-containing and phosphonatebearing complexes.

Colloidal stability under physiological conditions is one of the most important factors in considering potential biological applications of nanomaterials [80]. To evaluate the potential of the MGICs for drug delivery, it is of vital importance that the MGICs be hydrodynamically stable in deionized water under physiological conditions. The hydrodynamic sizes of both acrylate-containing and bisphosphonate-bearing MGICs were monitored by DLS in PBS at $\mathrm{pH} 7.4$ and $37^{\circ} \mathrm{C}$ over 24 hours to mimic physiological conditions. The hydrodynamic sizes of the dispersed nanocomplexes were measured again after 7 days. Their intensity average diameters measured by DLS over 24 hours are shown in Figure 2. Based on these tests, the MGICs had stable sizes in simulated physiological conditions for at least 24 hours, and the sizes remained unchanged even after 7 days. Our prior experience has shown that if the polymer begins to desorb from the nanoparticle surface, it leads to aggregation over time and eventually to sedimentation of the metal or metal oxides $[73,81]$. The relatively stable sizes of these MGICs suggest that adhesion between the polymers and the magnetite surfaces was sufficient for the polymers to remain stably bound.

2.3. Cisplatin- and Carboplatin-Loaded MGICs. To evaluate the potential of the MGICs as drug carriers, cisplatin and carboplatin were loaded into the hexyl bisphosphonate MGICs. The targeted amounts of both platinum drugs was $20 \mathrm{wt} \%$. cis-Dichlorodiammineplatinum(II) (cisplatin (CPT)) and cisdiammine(cyclobutane-1,1-dicarboxylate-O, $\mathrm{O}^{\prime}$ ) platinum(II) (carboplatin (CAPT)) are well-known platinum anticancer drugs. Cisplatin is one of the first-generation platinum drugs that remain one of the top choices for treatments of numerous malignant tumors including breast and prostate cancer [82]. However, it has poor water solubility and low selectivity towards tumor cells. It causes severe side effects such as acute nephrotoxicity and chronic neurotoxicity [83]. Carboplatin, a cisplatin analogue, belongs to the second-generation cancer 


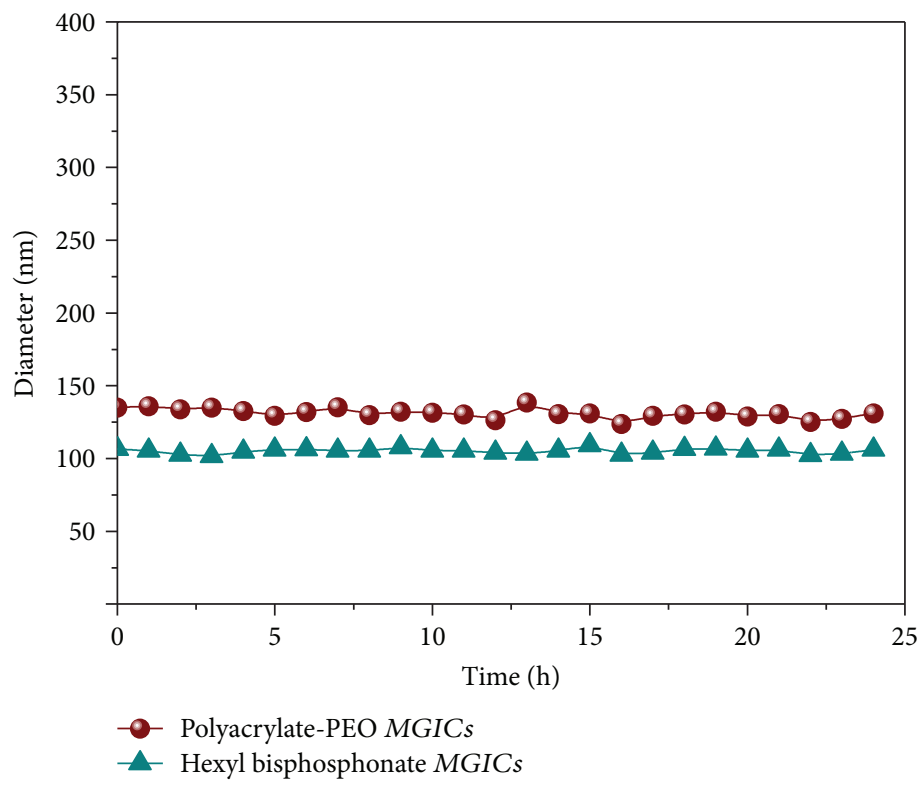

FIgURE 2: Hydrodynamic stability tests of the MGICs in simulated physiological conditions.

drugs and has better water solubility and less toxicity. Carboplatin is now widely used to treat ovarian cancer [36]. Encapsulating these platinum drugs into the MGIC nanocarriers may solve the problem of low water solubility for cisplatin.

It is known that the chloride ligands on cisplatin can be substituted by reactive groups such as carboxylates and phosphonates [21,47]. The cisplatin and carboplatin drug loading into the magnetite-graft ionomer complexes utilized a similar experimental procedure that was employed for synthesizing manganese(II)-graft ionomer complexes [47]. The cisplatin loading utilized a mixed solvent of 9:1 deionized water:dimethylsulfoxide (DMSO) by dissolving the drug in DMSO and dispersing the magnetite-graft ionomer complex in water (due to the poor water solubility of the drug). An unsuccessful attempt to load the cisplatin in only water as the reaction medium was made. Carboplatin has good water solubility, and thus, the loading process was performed in complete aqueous media. It is noteworthy that the dicarboxylate ligand in carboplatin binds to the platinum more strongly than individual chlorides do on cisplatin. A recent study [84] indicated that the ligands in carboplatin are not replaced under the conditions that were used for loading the drug into the complexes in the present work. It is likely that the phosphonate anions chelate the platinum without replacing the dicarboxylate ligands. Residual free drug was removed by centrifuging the dispersions through a membrane cassette. The cisplatin- (carboplatin-) loaded MGICs were redispersed in deionized water and were recovered by freeze-drying. This drying procedure was necessary to avoid premature drug release and any agglomeration of the nanoparticles that might have been introduced by heating.

Based on inductively coupled plasma atomic emission spectroscopy (ICP-AES) results, $8.7 \mathrm{wt} \%$ of platinum was loaded in the cisplatin-loaded MGICs, while $6.9 \mathrm{wt} \%$ was incorporated into the carboplatin-loaded MGICs. The targeted amount of platinum was $20 \mathrm{wt} \%$ in both cases. Although the drug loading efficiencies were significantly lower than the charged amount of platinum, the results do suggest that MGICs have the capacity to encapsulate platinum drugs. A possible explanation for the relatively low drug loadings is that the magnetite was in the form of small aggregates and that such aggregates prevented loading of more platinum drugs into the complexes. It could also be attributed to insufficient reaction times for the loading processes, so additional work would be required to understand how the reaction times affect the drug loading capacities. It was also found that the drug loading procedures did not cause significant loss of magnetite (within $0.5 \mathrm{wt} \%$ ), as determined by ICP-AES. The physicochemical properties of the cisplatin- and carboplatin-loaded hexyl bisphosphonate MGICs were measured as shown in Table 1 . The sizes increased slightly after drug loading, and the PDIs remained unchanged. This indicated that the drug had not affected the colloidal stability of the MGICs. Their zeta potentials decreased slightly, and this can be explained by the fact that part of the remaining anions on the polymers were sequestered into the cores of the micellar MGICs. These results are in good agreement with our previous studies on drug-loaded complexes, which indicate successful drug loading [21]. The results also strongly suggest that there is sufficient binding strength between the magnetite and the graft copolymers.

2.4. Transverse Relaxivities of MGICs. Magnetite nanoparticles have been demonstrated to be versatile MRI contrast agents $[24,25,85,86]$. To evaluate the potential for MRI applications with the MGICs, the proton transverse relaxivities $\left(r_{2} s\right)$ were measured at the physiological temperature $\left(37^{\circ} \mathrm{C}\right)$ and a magnetic field strength of 1.4 tesla (corresponding to a proton Larmor frequency of $60 \mathrm{MHz}$ ). This corresponds to a common clinical field strength. There are two types of NMR relaxations which generate magnetic resonance images: longitudinal relaxation $\left(\mathrm{T}_{1}\right.$ recovery) and 


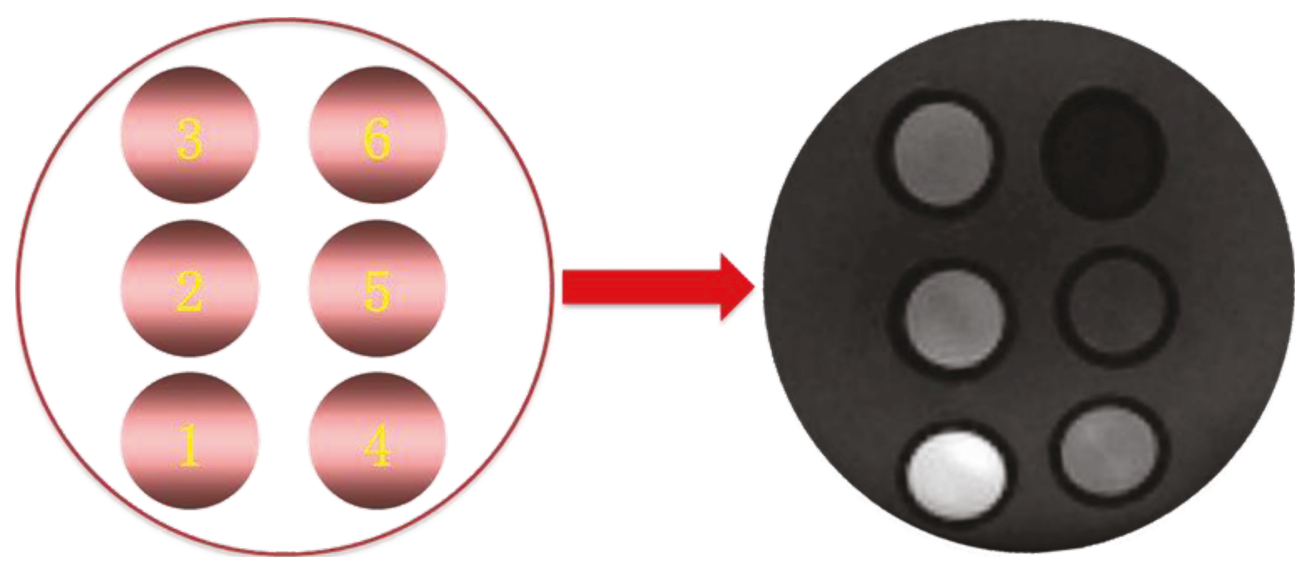

Figure 3: Phantom MRI images of the hexyl bisphosphonate MGICs at 4.7 tesla. Concentrations of iron in each tube were (1) 0, (2) 12.5, (3) 25, (4) 50, (5) 100, and (6) $200 \mu \mathrm{M} \mathrm{Fe.}$

transverse relaxation $\left(\mathrm{T}_{2}\right.$ decay). When magnetic nanoparticles such as magnetite are delivered in tissues, contrast enhancement is generated by shortening of both types of relaxations of surrounding protons. While MRI contrast agents affect both $\mathrm{T}_{1}$ and $\mathrm{T}_{2}$, magnetite nanoparticles are typically categorized as $\mathrm{T}_{2}$ contrast agents by applying $\mathrm{T}_{2}$-weighted pulse sequences [87]. $\mathrm{T}_{2}$ contrast agents decrease signal intensity, thus creating negative (dark) contrast enhancements in $\mathrm{T}_{2}$-weighted images [88]. For magnetite nanoparticles, $r_{2}$ is a normalized transverse contrast enhancement indicator. It can be calculated based on the slope of the measured transverse relaxation rate $\left(R_{2}\right)$ over iron concentration (mM Fe). Higher values of $r_{2}$ correlate with greater contrast [89].

The transverse relaxivities of the hexyl bisphosphonate MGICs were compared to our previously reported magnetic block ionomer complexes (MBICs) and MBIClusters as well as to a commercial $\mathrm{T}_{2}$-weighted MRI contrast agent Feridex IV. The hexyl bisphosphonate MGICs had a transverse relaxivity $\left(r_{2}\right)$ of $244 \mathrm{~s}^{-1}(\mathrm{mM} \mathrm{Fe})^{-1}$ and a longitudinal relaxivity $\left(r_{1}\right)$ of $3.3 \mathrm{~s}^{-1}(\mathrm{mM} \mathrm{Fe})^{-1}$. The high transverse relaxivity value is 2-4 times higher than the MBICs and almost sixfold higher than the commercial iron $\mathrm{T}_{2}$ contrast agent Feridex IV $\left(r_{2}=41 \mathrm{~s}^{-1}(\mathrm{mM} \mathrm{Fe})^{-1}\right.$ at $37^{\circ} \mathrm{C}$ and $\left.1.5 \mathrm{~T}\right)$ [21, 90]. The MGICs may be in the form of small clusters based on DLS results. Previous findings in our group suggested that small aggregates lead to significant increases in relaxivities [81]. Such a high relaxivity suggests that the MGICs may be sensitive contrast agents for MRI applications.

To further demonstrate that the MGICs have potential as negative contrast agents, phantom MRI images using the hexyl bisphosphonate MGICs were obtained (Figure 3). Significant contrast was observed at an iron concentration of $100 \mu \mathrm{M}$, and complete signal losses were observed at an Fe concentration of $200 \mu \mathrm{M}$. The relaxivities of the MGICs are in the range with the results from our and other previous reports of magnetic iron oxide nanoparticles that have similar sizes $[21,91,92]$.

Comparisons of transverse relaxivities between the drugfree and drug-loaded hexyl bisphosphonate MGICs were made (Figure 4). It was found that the cisplatin-loaded

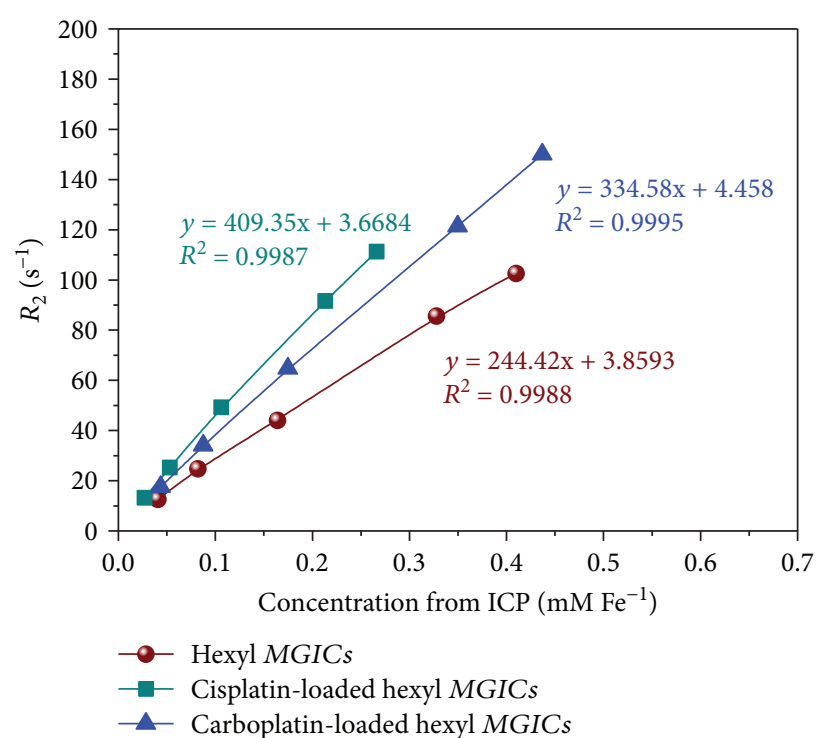

Figure 4: Transverse relaxivities of drug-free and drug-loaded hexyl bisphosphonate MGICs.

MGICs had a transverse relaxivity of $409 \mathrm{~s}^{-1}(\mathrm{mM} \mathrm{Fe})^{-1}$, while the carboplatin-loaded complex was $335 \mathrm{~s}^{-1}(\mathrm{mM} \mathrm{Fe})^{-1}$. The transverse relaxivity of the MGICs without a platinum drug was $244 \mathrm{~s}^{-1}(\mathrm{mM} \mathrm{Fe})^{-1}$. The longitudinal relaxivities increased slightly from 3.3 to $4.3 \mathrm{~s}^{-1}$ (mM Fe) ${ }^{-1}$ after drug loading. Since higher transverse relaxivities correlate with better contrast and magnetite generates dark (black) images, the drugloaded hexyl bisphosphonate MGICs generate darker $\mathrm{T}_{2}$-weighted images than drug-free ones do. It remains unclear whether the drug-free and drug-loaded complexes can generate $\mathrm{T}_{2}$-weighted images with significant differences in vivo. If they can generate MRI images with striking differences and such differences can be quantified, it may indicate the ability to track drug release by MRI, and this would represent a significant advance to understand and take advantage of the drug release kinetics of such complexes. 


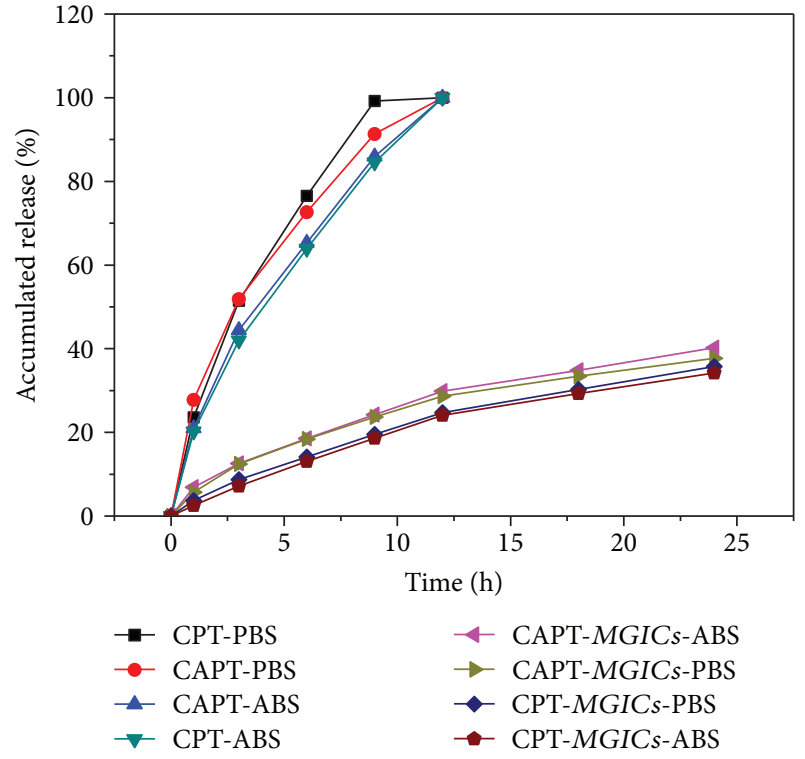

FIgURE 5: Drug release profiles with and without MGIC nanocarriers in $\mathrm{ABS}$ and $\mathrm{PBS}$ at $37^{\circ} \mathrm{C}$.

2.5. In Vitro Release Profiles of Cisplatin and Carboplatin from MGICs at pH 4.6 and 7.4. The drug release profiles from cisplatin- and carboplatin-loaded hexyl bisphosphonate MGICs were measured at $37^{\circ} \mathrm{C}$ by dialyzing the complexes and measuring platinum concentrations in the reception media by ICP-AES. The buffers used for the experiments were acetate buffer solution (ABS, $\mathrm{pH} 4.6$ ) to simulate the endosomal environment and PBS ( $\mathrm{pH} 7.4$ ) to mimic the physiological $\mathrm{pH}$. The experiments were performed over 24 hours. The amount of accumulated drug release as a function of time is shown in Figure 5. Free cisplatin and carboplatin fully transported into the reception medium over 12 hours. Cisplatin- and carboplatin-loaded hexyl bisphosphonate MGICs released the drugs more slowly and in a sustained manner. After 24 hours, approximately $40 \mathrm{wt} \%$ of the platinum was released. It has been reported [93] that the $\mathrm{pK}_{\mathrm{a} 1} \mathrm{~s}$ of such ammonium-bearing phosphonic acids were below 4 while the $\mathrm{pK}_{\mathrm{a} 2} \mathrm{~s}$ were between 6 and 7.4. This indicated that the amount of phosphonate anions at $\mathrm{pH} 4.6$ was only half that at $\mathrm{pH} 7.4$. Still, the rates of drug release at pH 4.6 and 7.4 were not significantly different. This demonstrated strong binding between the phosphonate and the magnetite and platinum drugs. With fewer phosphonate anions present at lower $\mathrm{pH}$, the drugs did not release significantly faster. Overall, sustained release of cisplatin and carboplatin was achieved by loading them into the MGIC nanocarriers. The MGIC complexes represent promising candidates as drug carriers for delivery applications.

2.6. SAR Measurements. A hexyl bisphosphonate MGIC aqueous dispersion $\left(3.5 \mathrm{mg} \cdot \mathrm{mL}^{-1}, 0.5 \mathrm{~mL}\right)$ was found to release heat upon exposure to an AC magnetic field at $480 \mathrm{~A}$ and $206 \mathrm{kHz}$. The temperature of the nanoparticle dispersion increased from 37 to $41^{\circ} \mathrm{C}$ after applying the $\mathrm{AC}$ magnetic field for 10 minutes (Figure 6). The SAR values of the hexyl bisphosphonate MGICs was calculated to be

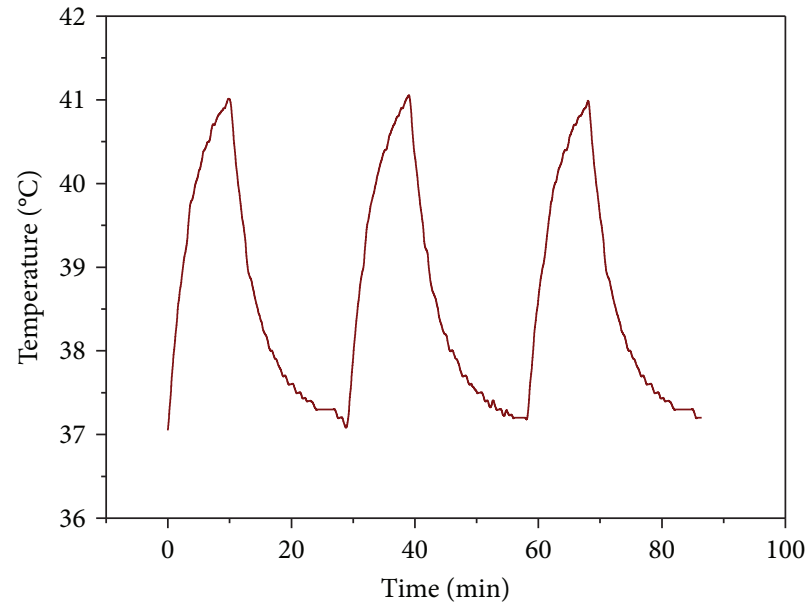

Figure 6: Calorimetric measurement of the hexyl bisphosphonate MGICs.

$77.0 \mathrm{~W} \cdot \mathrm{g}^{-1}$ at a field strength of $30 \mathrm{kA} \cdot \mathrm{m}^{-1}$ and a frequency of $206 \mathrm{kHz}$ [94-96]. This may potentially allow hyperthermia treatment and/or heat-induced drug release. Such benefits further increased the versatility of the MGICs for biomedical applications.

\section{Conclusion}

In summary, novel bisphosphonate graft ionic copolymermagnetite complexes have been synthesized and characterized. They displayed relatively uniform sizes with narrow size distributions after self-assembly in aqueous media. They also showed good colloidal stability in simulated physiological conditions for up to 7 days. The antitumor drugs, cisplatin and carboplatin, were successfully loaded into the MGICs. Sustained drug release of both cisplatin and carboplatin were achieved in both simulated endosomal and physiological conditions. The drug-free and drug-loaded MGICs exhibited excellent contrast enhancements in comparison with the commercial $\mathrm{T}_{2}$-weighted MRI agent Feridex IV. Therefore, the bisphosphonate graft ionic copolymer-magnetite complexes may be promising candidates for dual MRI imaging and drug delivery, with the possibility of triggered drug release and hyperthermia treatment, making it more versatile in potential drug delivery applications.

\section{Materials and Methods}

4.1. Materials. Diethyl vinyl phosphonate (Epsilon Chimie, $>98 \%$ ), anhydrous dimethylsulfoxide (DMSO), and dichloromethane (EMD Chemicals, anhydrous, 99.8\%) were used as received. Phosphate-buffered saline (PBS) was obtained from MediaTech. Acetate buffer solution (ABS) was purchased from Fluka Analytical. Methanol (anhydrous, 99.9\%), hexane (99.9\%), dichloromethane (99.9\%), chloroform (99.9\%), diethyl ether (anhydrous, 99.8\%), nitric acid aqueous solution (69.3\%), and dialysis tubing (Spectra/Por, 3500 and 12,000 MWCO), all from Fisher Scientific, were used as received. $N, N$-Dimethylformamide (DMF, 99.9\%), 3-amino- 
1-propanol (>99\%), 6-amino-1-hexanol (>99\%), sodium sulfate (anhydrous, 99\%), triethylamine $(>99.5 \%)$, sodium hydroxide (97\%), poly(ethylene oxide) monomethyl ether $\left(M_{n}=5085\right), 2,2^{\prime}$-azobisisobutyronitrile (AIBN, 98\%), sodium chloride (>99.5\%), oleic acid ( $90 \%$, technical grade), iron(III) chloride hexahydrate (97\%), trioctylamine, sodium oleate, and aqueous tetramethylammonium hydroxide solution $(25 \% \mathrm{wt} / \mathrm{v})$ were purchased from Sigma-Aldrich and used as received. Acryloyl chloride (97\%), methacryloyl chloride (97\%), and bromotrimethylsilane (TMSBr, 97.0\%) were fractionally distilled before use. Deionized water was obtained through a Milli-Q A10 water purification system (EMD Millipore, MA). Slide-A-Lyzer dialysis cassettes (MWCO 3500) were obtained from Thermo Scientific. Centrifugal filter units (MWCO $10 \mathrm{k}$ ) were obtained from EMD Millipore. A permanent magnet made of $\mathrm{NdFeB}$ with a diameter of $11 / 16^{\prime \prime}$ and a thickness of $1 / 4^{\prime \prime}$ was purchased from K\&J Magnetics. It was axially magnetized with a surface field of 3880 Gauss.

4.2. Characterization. ${ }^{1} \mathrm{H}$ NMR spectral analyses were performed on a Bruker Avance II 500 NMR operating at $500 \mathrm{MHz} .{ }^{31} \mathrm{P}$ NMR spectral analyses were obtained on a Varian Inova 400 NMR operating at $161.91 \mathrm{MHz}$. Parameters utilized for the ${ }^{31} \mathrm{P}$ NMR were a $45^{\circ}$ pulse and $1 \mathrm{~s}$ relaxation delay with 128 scans. All spectra of the monomers and phosphonate polymers were obtained in $\mathrm{CDCl}_{3}$. Spectra of the phosphonic acid polymers were obtained in $\mathrm{D}_{2} \mathrm{O}$ by adjusting the $\mathrm{pH}$ to 7.4 with $\mathrm{NaOD}$.

Intensity average diameters were determined by dynamic light scattering (DLS) measurements using the Zetasizer Nano ZS (Malvern Instruments, Software versus 7.11) equipped with a $4.0 \mathrm{~mW}$ solid-state He-Ne laser $(\lambda=633 \mathrm{n}$ $\mathrm{m})$ at a scattering angle of $173^{\circ}$ and at $25 \pm 0.1^{\circ} \mathrm{C}$. DLS uses an algorithm based on Mie theory that converts timevarying scattering intensities to hydrodynamic diameters of particles in suspension. For DLS analysis, the drug-free or drug-loaded complexes were dispersed in deionized water at a concentration of $1 \mathrm{mg} \mathrm{mL}^{-1}$. Each dispersion was sonicated for $3 \mathrm{~min}$ in a $75 \mathrm{~T}$ VWR Ultrasonicator $(120 \mathrm{~W}$, $45 \mathrm{kHz}$ ) before transferring it into a polystyrene cuvette for analysis. All measurements were done in triplicate, and the averages are reported.

The amounts of platinum that were loaded into the complexes were quantified by ICP-AES. The amount of iron in both the drug-free and drug-loaded complexes was also quantified by ICP-AES. The drug-free or drug-loaded complexes $(2.5 \mathrm{mg})$ were dispersed in deionized water $(10 \mathrm{~mL})$ in a $20 \mathrm{~mL}$ vial and sonicated for $3 \mathrm{~min}$. The dispersion $(1 \mathrm{~mL})$ was then charged to a new vial, and concentrated nitric acid $(4 \mathrm{~mL})$ was added to digest the magnetite into their water-soluble nitrate salts with vigorous stirring for $72 \mathrm{~h}$. The obtained solution $(1 \mathrm{~mL})$ was diluted with DI water $(9 \mathrm{~mL})$ and was submitted for ICP-AES measurements. All experiments were performed in triplicate, and the averages are reported.

Transmission electron microscopy (TEM) was performed on a JEOL 200CX TEM instrument operating at an acceleration voltage of $120 \mathrm{kV}$. The samples with the oleic acid-coated magnetite and the hexyl bisphosphonate MGICs were prepared by casting a drop of the chloroform solution onto amorphous carbon-coated copper grids.

Phantom magnetic resonance imaging was performed to demonstrate $\mathrm{T}_{2}$ shortening effects of the MGICs. The particles were dispersed in PBS at iron concentrations ranging from 0 to $200 \mu \mathrm{M}$ Fe. The dispersions were transferred to $1.5 \mathrm{~mL}$ Eppendorf tubes and mounted in a $1.5 \mathrm{wt} \%$ agarose gel in a glass container. MRI was performed on a $4.7 \mathrm{~T}$ small animal MRI scanner with a $40 \mathrm{~cm}$ horizontal bore (Bruker). $\mathrm{T}_{2}$-weighted $\mathrm{MR}$ images were acquired with a spin-echo sequence with repetition time $(\mathrm{TR})=2500 \mathrm{~ms}$, echo time $(\mathrm{TE})=100 \mathrm{~ms}$, flip angle $=180^{\circ}$, matrix size $=128 \times 128$, and slice thickness $=1 \mathrm{~mm}$.

The SAR of the hexyl bisphosphonate MGICs was measured and calculated with an EASYHEAT Induction Heating System produced by Ameritherm. The calorimetric measurement setup is described in the supplementary document (Figure S1).

\subsection{Synthesis of Poly(ammonium Bisphosphonate-g-ethylene} Oxide) and Poly(acrylate-g-ethylene Oxide) Copolymers. Synthesis methods for making a poly(hexyl ammonium bisphosphonic acid methacrylate-g-ethylene oxide) and a poly(propyl ammonium bisphosphonic acid methacrylate- $g$ ethylene oxide) monomer and polymer have been previously reported (Figures S2 and S3) [76]. The expected structures were confirmed by ${ }^{1} \mathrm{H}$ and ${ }^{31} \mathrm{P}$ NMR (Figures S4 and S5) $[47,76]$. The poly(acrylic acid- $g$-ethylene oxide) was prepared by conventional free radical polymerization and is described in a previous paper [47]. The poly(hexyl ammonium bisphosphonic acid methacrylate-g-ethylene oxide) and the poly(propyl ammonium bisphosphonic acid methacrylate- $g$ ethylene oxide) polymers contained approximately $60 \mathrm{wt} \%$ of the bisphosphonate graft ionomer and about $40 \mathrm{wt} \%$ of PEO. The poly(acrylic acid)-g-poly(ethylene oxide) contained about $50 \mathrm{wt} \%$ of poly(acrylic acid) and $50 \mathrm{wt} \%$ of PEO, as determined by ${ }^{1} \mathrm{H}$ NMR (Figures S4 and S6).

4.4. Synthesis of Magnetite Nanoparticles. Magnetite nanoparticles were synthesized by a known procedure that utilized thermal decomposition of an iron oleate precursor in trioctylamine as a high-boiling solvent [76]. The synthesis consisted of two steps: (1) synthesis of the iron oleate precursor and (2) its conversion to magnetite nanoparticles. Iron(III) chloride hexahydrate $(6.50 \mathrm{~g}, 0.95 \mathrm{mmol})$ was dissolved in deionized water $(24 \mathrm{~mL})$ in a $250 \mathrm{~mL}$ beaker and sonicated for $10 \mathrm{~min}$. Sodium oleate $(21.9 \mathrm{~g}, 71.9 \mathrm{mmol})$ then deionized water $(12 \mathrm{~mL})$, ethanol $(48 \mathrm{~mL})$, and hexane $(84 \mathrm{~mL})$ were added. The mixture was placed in a $500 \mathrm{~mL}$, three-necked, round-bottom flask equipped with a heating mantle and mechanical agitation $(200 \mathrm{rpm})$ and purged with $\mathrm{N}_{2}$ for $5 \mathrm{~min}$. The mixture was heated to $70^{\circ} \mathrm{C}$ with a constant heating rate of $6.7^{\circ} \mathrm{C} / \mathrm{min}$ and was kept at $70^{\circ} \mathrm{C}$ for another $4 \mathrm{~h}$. The iron-oleate complex, which partitioned into the upper organic layer, was washed three times with deionized water $(20 \mathrm{~mL}$ each) in a separatory funnel. The organic layer was collected, and the solvent was removed by rotary 


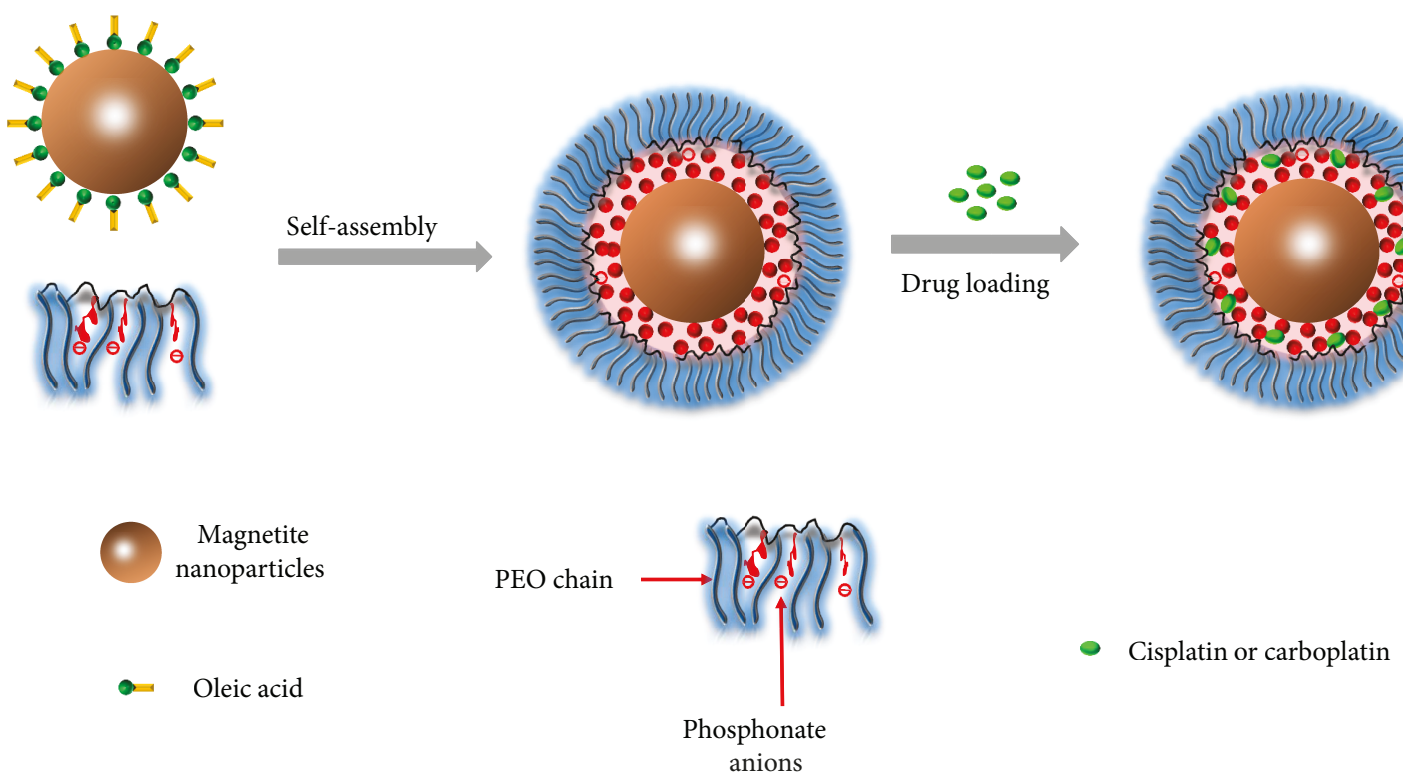

Scheme 1: Synthesis of the MGICs and cisplatin and carboplatin loading.

evaporation. The viscous product was dried under vacuum at $70^{\circ} \mathrm{C}$ for $24 \mathrm{~h}$ to yield the iron-oleate precursor.

The magnetite nanoparticles were prepared by mixing the iron oleate precursor $(20.5 \mathrm{~g})$ with oleic acid ( $3.3 \mathrm{~g}$, $11.7 \mathrm{mmol})$ and trioctylamine $(114 \mathrm{~mL})$ and sonicating for $15 \mathrm{~min}$. The mixture was charged to a $500 \mathrm{~mL}$, three-necked, round-bottom flask equipped with a heating mantle and mechanical agitation (200 rpm) and purged with $\mathrm{N}_{2}$ for $30 \mathrm{~min}$. The reaction mixture was heated to $350^{\circ} \mathrm{C}$ at a constant rate of $3.3^{\circ} \mathrm{C} / \mathrm{min}$ then kept at $350^{\circ} \mathrm{C}$ for $30 \mathrm{~min}$. The reaction mixture was cooled to room temperature and diluted with cold ethanol. The mixture was placed in centrifuge tubes and centrifuged at $7500 \mathrm{rpm}$ for $15 \mathrm{~min}$. The liquid was decanted, and the oleic acid and amine-coated magnetite nanoparticles were recovered from the centrifuge tubes. The magnetite nanoparticles were purged with $\mathrm{N}_{2}$ overnight at room temperature to yield a black solid.

4.5. Synthesis of Magnetite-Graft Ionomer Complexes (MGICs). The synthetic method for preparing the magnetitegraft ionomer complexes (MGICs) was adapted from a previously reported method developed by our group [21]. The oleic acid-coated magnetite nanoparticles $(50 \mathrm{mg})$ were dispersed in anhydrous chloroform $(5 \mathrm{~mL})$ in a $20 \mathrm{~mL}$ vial, and the mixture was sonicated for $10 \mathrm{~min}$. Poly(ammonium bisphosphonic acid methacrylate- $g$-PEO) (100 mg) or poly(acrylic acid-g-PEO) (100 mg) was charged into a separate vial equipped with a magnetic stir bar. Anhydrous DMF ( $5 \mathrm{~mL}$ ) was added to dissolve the polymer, and the mixture was sonicated for $10 \mathrm{~min}$. The magnetite dispersion was added dropwise into the polymer solution while sonicating, followed by purging with $\mathrm{N}_{2}$ for $5 \mathrm{~min}$. The reaction mixture was further sonicated for $4 \mathrm{~h}$, and the water in the sonicator was changed every $30 \mathrm{~min}$. The mixture was stirred at room temperature for $48 \mathrm{~h}$. The mixture was then precipitated into hexane $(20 \mathrm{~mL})$ five times. A permanent magnet was placed under the vial to attract the complexes while the supernatant was decanted to remove any solvent, free oleic acid, or other residues. The remaining solid was washed with diethyl ether $(20 \mathrm{~mL}) 3$ times, and the supernatant was decanted. The nanoparticles were purged with $\mathrm{N}_{2}$ for $2 \mathrm{~h}$ to remove most of the solvent, then they were dispersed in deionized water $(10 \mathrm{~mL})$ and the $\mathrm{pH}$ was adjusted to 7.4 using a $1 \mathrm{~N}$ aqueous $\mathrm{NaOH}$ solution. The dispersion was sonicated for $20 \mathrm{~min}$. It was transferred to dialysis tubing with a $12 \mathrm{k}$ MWCO and dialyzed against deionized water (4L) for $24 \mathrm{~h}$. Finally, the MGICs were recovered by freeze-drying for 2 days. The polymer-magnetite complexation process is shown in Scheme 1.

4.6. Preparation of Cisplatin-Loaded MGICs. The magnetite complex with the poly(hexyl ammonium bisphosphonic acid methacrylate- $g$-PEO) was used to load drugs. MGICs (50 mg) were dispersed in deionized water $(4.5 \mathrm{~mL})$ in a $20 \mathrm{~mL}$ vial equipped with a magnetic stir bar. The dispersion was sonicated for $5 \mathrm{~min}$. Cisplatin $(20.1 \mathrm{mg})$ was charged into a separate vial, and DMSO $(0.5 \mathrm{~mL})$ was added to dissolve the cisplatin. This was followed by sonication for $5 \mathrm{~min}$. The cisplatin solution was added dropwise into the MGIC dispersion while sonicating. The mixture was sonicated for $5 \mathrm{~min}$ then stirred at room temperature for $12 \mathrm{~h}$. The mixture was transferred to a membrane centrifuge unit with a $10 \mathrm{k}$ MWCO and was centrifuged at $5 \mathrm{krpm}$ for $1 \mathrm{~h}$. The particles were collected from the membrane, dispersed in deionized water $(10 \mathrm{~mL})$, and transferred to a $20 \mathrm{~mL}$ vial. The dispersion was freeze-dried for 2 days. The targeted wt $\%$ of platinum was $20 \%$, and this was the same for both cisplatin and carboplatin. The drug loading process is shown in Scheme 1.

4.7. Synthesis of Carboplatin-Loaded MGICs. MGICs (50 mg) were dispersed in phosphate buffer $(0.01 \mathrm{~N}, 5 \mathrm{~mL})$ in a $20 \mathrm{~mL}$ vial equipped with a magnetic stir bar and sonicated for 
$5 \mathrm{~min}$. Carboplatin (30.7 mg) was charged into a separate vial, and phosphate buffer $(0.01 \mathrm{~N}, 5 \mathrm{~mL})$ was added to dissolve the carboplatin. The solution was sonicated for $5 \mathrm{~min}$. The carboplatin solution was added dropwise into the MGIC dispersion while sonicating, and the mixture was sonicated for 5 additional min. The mixture was stirred at room temperature for $24 \mathrm{~h}$. The work-up procedures were the same as described for cisplatin.

4.8. Relaxivity Measurements. Proton transverse relaxation times $\left(\mathrm{T}_{2}\right)$ and longitudinal relaxation times $\left(\mathrm{T}_{1}\right)$ were measured on a Model MQ-60 NMR Analyzer (Bruker Minispec) at a magnetic field strength of $1.4 \mathrm{~T}$ corresponding to a proton Larmor frequency of $60 \mathrm{MHz} . \mathrm{T}_{2}$ s were obtained from fitting a monoexponential decay curve to signal data generated by a Carr-Purcell-Meiboom-Gill (CPMG) spin-echo pulse sequence with an echo spacing of $0.5 \mathrm{~ms}$ and a repetition time of $5 \mathrm{~s}$. $\mathrm{T}_{1} \mathrm{~s}$ were obtained from fitting a monoexponential recovery curve to signal data generated with an inversion recovery pulse sequence using ten logarithmically spaced inversion times between 50 and 10,000 ms. Either drug-free or drug-loaded MGICs were dispersed in deionized water to generate a series of dispersions with concentrations of 0.1 , $0.08,0.04,0.02$, and $0.01 \mathrm{mg} \cdot \mathrm{mL}^{-1}$, and each was sonicated for $3 \mathrm{~min}$ in a $75 \mathrm{~T}$ VWR Ultrasonicator $(120 \mathrm{~W}, 45 \mathrm{kHz})$. Each dispersion $(500 \mu \mathrm{L})$ was transferred into a $7.5 \mathrm{~mm}$ NMR tube, and measurements were made at $37.5^{\circ} \mathrm{C}$ after equilibration for $15 \mathrm{~min}$. The transverse relaxivities $\left(r_{2} \mathrm{~s}\right)$ and longitudinal relaxivities $\left(r_{1} s\right)$ were calculated from the leastsquare fits of the relaxation rates $\left(R_{2}, R_{1}\right)$, which were the inverses of the relaxation times $\left(\mathrm{T}_{2}, \mathrm{~T}_{1}\right)$ as a function of iron concentration ( $\mathrm{mM} \mathrm{Fe}$ ). To measure the concentration of $\mathrm{Fe}$ in each tube, each dispersion $(1 \mathrm{~mL})$ was charged to a $20 \mathrm{~mL}$ vial and concentrated nitric acid $(4 \mathrm{~mL})$ was added. The vials were sealed with Parafilm and shaken vigorously for $72 \mathrm{~h}$. Each solution $(1 \mathrm{~mL})$ was diluted with deionized water $(9 \mathrm{~mL})$ and was submitted for ICP-AES to measure the concentrations of iron. This was done in triplicate, and the averages are reported.

4.9. In Vitro Release of Cisplatin or Carboplatin from MGICs. To determine the release of cisplatin (carboplatin) from the drug-loaded MGICs, a drug release study was performed at $37^{\circ} \mathrm{C}$ for $24 \mathrm{~h}$. ABS ( $\mathrm{pH} 4.6$ ) was used to simulate the endosomal environment, and PBS ( $\mathrm{pH} 7.4$ ) was used to mimic physiological conditions. ABS or PBS $(150 \mathrm{~mL})$ was charged into a $250 \mathrm{~mL}$ beaker equipped with a magnetic stir bar. The solution was heated to $37^{\circ} \mathrm{C}$ for $1 \mathrm{~h}$. A dialysis cassette with a $4 \mathrm{k}$ MWCO was hydrated with deionized water, then ABS (or PBS). Cisplatin- (carboplatin-) loaded MGICs (20 mg), or free cisplatin (carboplatin) $(10 \mathrm{mg})$, were dispersed in ABS or PBS ( $5 \mathrm{~mL}$ each). The dispersion was sonicated for $1 \mathrm{~min}$. Each dispersion $(3 \mathrm{~mL})$ was transferred into a dialysis cassette. An aliquot of the remaining dispersion $(1 \mathrm{~mL})$ was charged into another vial, followed by dilution with ABS or PBS $(9 \mathrm{~mL})$, and was submitted for ICP-AES measurement to determine the wt $\%$ of Pt. Each cassette was placed into a beaker equipped with a stir bar and either ABS or PBS $(150 \mathrm{~mL})$. The beakers were sealed with Parafilm to avoid evaporation of the liquid. The beakers were stirred at $37^{\circ} \mathrm{C}$ for $24 \mathrm{~h}$. At $0,1,3,6,9,12,18$, and $24 \mathrm{~h}$, the beakers were shaken vigorously by hand, and the reception media were flushed with a syringe a few times. Solutions from the reception media $(10 \mathrm{~mL})$ were charged into separate vials. At each time point, fresh ABS or PBS $(10 \mathrm{~mL})$ was replenished to maintain constant volume in the reception media. All the samples of reception media, as well as the starting dispersions in the vials, were submitted for ICP-AES measurements to determine the wt $\%$ of Pt.

\section{Data Availability}

The data used to support the findings of this study are available from the corresponding author upon request.

\section{Conflicts of Interest}

The authors declare that they have no conflicts of interest.

\section{Acknowledgments}

The authors are grateful for the support of the National Science Foundation under contracts DMR 0805179, DMR 1106182, and DMR 1263248.

\section{Supplementary Materials}

Experimental setup for calorimetric measurements, synthesis of a hexylamino bisphosphonate methacrylate monomer, synthesis of poly(hexyl ammonium bisphosphonic acid methacrylate)-g-PEO copolymers, ${ }^{1} \mathrm{H}$ and ${ }^{31} \mathrm{P}$ NMR spectra of the phosphonate esters of the poly(propyl ammonium bisphosphonate methacrylate)-g-PEO copolymers before and after selective hydrolysis, the ${ }^{1} \mathrm{H}$ NMR spectrum of the PEO- $g$-PAA, and additional representative images of MGICs following complexation with copolymers that led to a cluster formation are available in Figures S1-S7. (Supplementary Materials)

\section{References}

[1] D. K. Kim and J. Dobson, "Nanomedicine for targeted drug delivery," Journal of Materials Chemistry, vol. 19, no. 35, pp. 6294-6307, 2009.

[2] A. V. Kabanov, E. V. Batrakova, and V. Y. Alakhov, "Pluronic ${ }^{\circledR}$ block copolymers as novel polymer therapeutics for drug and gene delivery," Journal of Controlled Release, vol. 82, no. 2-3, pp. 189-212, 2002.

[3] S. P. Sherlock, S. M. Tabakman, L. Xie, and H. Dai, "Photothermally enhanced drug delivery by ultrasmall multifunctional FeCo/graphitic shell nanocrystals," ACS Nano, vol. 5, no. 2, pp. 1505-1512, 2011.

[4] Y. Tu, F. Peng, A. A. M. André, Y. Men, M. Srinivas, and D. A. Wilson, "Biodegradable hybrid stomatocyte nanomotors for drug delivery," ACS Nano, vol. 11, no. 2, pp. 1957-1963, 2017.

[5] X. Yuan, D. C. Marcano, C. S. Shin et al., "Ocular drug delivery nanowafer with enhanced therapeutic efficacy," ACS Nano, vol. 9, no. 2, pp. 1749-1758, 2015. 
[6] S. Mura, J. Nicolas, and P. Couvreur, "Stimuli-responsive nanocarriers for drug delivery," Nature Materials, vol. 12, no. 11, pp. 991-1003, 2013.

[7] J. Nicolas, S. Mura, D. Brambilla, N. Mackiewicz, and P. Couvreur, "Design, functionalization strategies and biomedical applications of targeted biodegradable/biocompatible polymer-based nanocarriers for drug delivery," Chemical Society Reviews, vol. 42, no. 3, pp. 1147-1235, 2013.

[8] N. Nishiyama, Y. Matsumura, and K. Kataoka, "Development of polymeric micelles for targeting intractable cancers," Cancer Science, vol. 107, no. 7, pp. 867-874, 2016.

[9] H. Kinoh, Y. Miura, T. Chida et al., "Nanomedicines eradicating cancer stem-like cells in vivo by $\mathrm{pH}$-triggered intracellular cooperative action of loaded drugs," ACS Nano, vol. 10, no. 6 , pp. 5643-5655, 2016.

[10] F. Li, C. Li, J. Liu et al., "Aqueous phase synthesis of upconversion nanocrystals through layer-by-layer epitaxial growth for in vivo X-ray computed tomography," Nanoscale, vol. 5, no. 15, pp. 6950-6959, 2013.

[11] C. Li, F. Li, T. Li et al., "A facile synthesis and photoluminescence properties of water-dispersible $\mathrm{Re}^{3+}$ doped $\mathrm{CeF}_{3}$ nanocrystals and solid nanocomposites with polymers," Dalton Transactions, vol. 41, no. 16, pp. 4890-4895, 2012.

[12] F. Li, C. Li, X. Liu et al., "Microwave-assisted synthesis and up-down conversion luminescent properties of multicolor hydrophilic $\mathrm{LaF}_{3}: \mathrm{Ln}^{3+}$ nanocrystals," Dalton Transactions, vol. 42, no. 6, pp. 2015-2022, 2013.

[13] L. A. Guzman, V. Labhasetwar, C. Song et al., "Local intraluminal infusion of biodegradable polymeric nanoparticles: a novel approach for prolonged drug delivery after balloon angioplasty," Circulation, vol. 94, no. 6, pp. 1441-1448, 1996.

[14] V. P. Torchilin, "Micellar nanocarriers: pharmaceutical perspectives," Pharmaceutical Research, vol. 24, no. 1, pp. 1-16, 2007.

[15] V. P. Torchilin, "Structure and design of polymeric surfactantbased drug delivery systems," Journal of Controlled Release, vol. 73, no. 2-3, pp. 137-172, 2001.

[16] G. Gaucher, M.-H. Dufresne, V. P. Sant, N. Kang, D. Maysinger, and J. C. Leroux, "Block copolymer micelles: preparation, characterization and application in drug delivery," Journal of Controlled Release, vol. 109, no. 1-3, pp. 169-188, 2005.

[17] K. T. Oh, T. K. Bronich, L. Bromberg, T. A. Hatton, and A. V. Kabanov, "Block ionomer complexes as prospective nanocontainers for drug delivery," Journal of Controlled Release, vol. 115, no. 1, pp. 9-17, 2006.

[18] M. Kamimura, J. O. Kim, A. V. Kabanov, T. K. Bronich, and Y. Nagasaki, "Block ionomer complexes of PEG-blockpoly(4-vinylbenzylphosphonate) and cationic surfactants as highly stable, $\mathrm{pH}$ responsive drug delivery system," Journal of Controlled Release, vol. 160, no. 3, pp. 486-494, 2012.

[19] X.-B. Xiong, A. Falamarzian, S. M. Garg, and A. Lavasanifar, "Engineering of amphiphilic block copolymers for polymeric micellar drug and gene delivery," Journal of Controlled Release, vol. 155, no. 2, pp. 248-261, 2011.

[20] K. Kataoka, A. Harada, and Y. Nagasaki, "Block copolymer micelles for drug delivery: design, characterization and biological significance," Advanced Drug Delivery Reviews, vol. 47, no. 1, pp. 113-131, 2001.

[21] N. Pothayee, N. Pothayee, N. Jain et al., "Magnetic block ionomer complexes for potential dual imaging and therapeutic agents," Chemistry of Materials, vol. 24, no. 11, pp. 20562063, 2012.

[22] A. Lavasanifar, J. Samuel, and G. S. Kwon, "Poly(ethylene oxide)-block-poly(l-amino acid) micelles for drug delivery," Advanced Drug Delivery Reviews, vol. 54, no. 2, pp. 169-190, 2002.

[23] N. Pothayee, S. Balasubramaniam, N. Pothayee et al., "Magnetic nanoclusters with hydrophilic spacing for dual drug delivery and sensitive magnetic resonance imaging," Journal of Materials Chemistry B, vol. 1, no. 8, pp. 1142-1149, 2013.

[24] H. M. Vishwasrao, A. M. Master, Y. G. Seo et al., "Luteinizing hormone releasing hormone-targeted cisplatin-loaded magnetite nanoclusters for simultaneous MR imaging and chemotherapy of ovarian cancer," Chemistry of Materials, vol. 28, no. 9, pp. 3024-3040, 2016.

[25] N. Pothayee, D. M. Cummings, T. J. Schoenfeld et al., "Magnetic resonance imaging of odorant activity-dependent migration of neural precursor cells and olfactory bulb growth," NeuroImage, vol. 158, pp. 232-241, 2017.

[26] R. Regmi, S. R. Bhattarai, C. Sudakar et al., "Hyperthermia controlled rapid drug release from thermosensitive magnetic microgels," Journal of Materials Chemistry, vol. 20, no. 29, pp. 6158-6163, 2010.

[27] A. P. Herrera, C. Barrera, and C. Rinaldi, "Synthesis and functionalization of magnetite nanoparticles with aminopropylsilane and carboxymethyldextran," Journal of Materials Chemistry, vol. 18, no. 31, pp. 3650-3654, 2008.

[28] C. Barrera, A. P. Herrera, and C. Rinaldi, "Colloidal dispersions of monodisperse magnetite nanoparticles modified with poly (ethylene glycol)," Journal of Colloid and Interface Science, vol. 329, no. 1, pp. 107-113, 2009.

[29] J.-F. Lutz, S. Stiller, A. Hoth, L. Kaufner, U. Pison, and R. Cartier, "One-pot synthesis of PEGylated ultrasmall ironoxide nanoparticles and their in vivo evaluation as magnetic resonance imaging contrast agents," Biomacromolecules, vol. 7, no. 11, pp. 3132-3138, 2006.

[30] S. Ghosh, S. GhoshMitra, T. Cai, D. R. Diercks, N. C. Mills, and D. A. L. Hynds, "Alternating magnetic field controlled, multifunctional nano-reservoirs: intracellular uptake and improved biocompatibility," Nanoscale Research Letters, vol. 5, no. 1, pp. 195-204, 2010.

[31] M. Creixell, A. P. Herrera, M. Latorre-Esteves, V. Ayala, M. Torres-Lugo, and C. Rinaldi, "The effect of grafting method on the colloidal stability and in vitro cytotoxicity of carboxymethyl dextran coated magnetic nanoparticles," Journal of Materials Chemistry, vol. 20, no. 39, pp. 8539-8547, 2010.

[32] R. Siegel, J. Ma, Z. Zou, and A. Jemal, "Cancer statistics, 2014," CA: A Cancer Journal for Clinicians, vol. 64, no. 1, pp. 9-29, 2014.

[33] S. W. Wyatt, W. R. Maynard, D. R. Risser, A. M. Hakenewerth, M. A. Williams, and R. Garcia, "All-cancers mortality rates approaching diseases of the heart mortality rates as leading cause of death in Texas," Southern Medical Journal, vol. 107, no. 1, pp. 19-23, 2014.

[34] A. Chilkoti, M. R. Dreher, D. E. Meyer, and D. Raucher, "Targeted drug delivery by thermally responsive polymers," Advanced Drug Delivery Reviews, vol. 54, no. 5, pp. 613-630, 2002.

[35] R. K. Jain, "Delivery of molecular medicine to solid tumors," Science, vol. 271, no. 5252, pp. 1079-1080, 1996. 
[36] I. Kostova, "Platinum complexes as anticancer agents," Recent Patents on Anti-Cancer Drug Discovery, vol. 1, no. 1, pp. 1-22, 2006.

[37] S. Pignata, G. Scambia, D. Katsaros et al., "Carboplatin plus paclitaxel once a week versus every 3 weeks in patients with advanced ovarian cancer (MITO-7): a randomised, multicentre, open-label, phase 3 trial," The Lancet Oncology, vol. 15, no. 4, pp. 396-405, 2014.

[38] E. Pujade-Lauraine, U. Wagner, E. Aavall-Lundqvist et al., "Pegylated liposomal doxorubicin and carboplatin compared with paclitaxel and carboplatin for patients with platinumsensitive ovarian cancer in late relapse," Journal of Clinical Oncology, vol. 28, no. 20, pp. 3323-3329, 2010.

[39] T. André, C. Boni, M. Navarro et al., "Improved overall survival with oxaliplatin, fluorouracil, and leucovorin as adjuvant treatment in stage II or III colon cancer in the MOSAIC trial," Journal of Clinical Oncology, vol. 27, no. 19, pp. 3109-3116, 2009.

[40] G. V. Scagliotti, P. Parikh, J. von Pawel et al., "Phase III study comparing cisplatin plus gemcitabine with cisplatin plus pemetrexed in chemotherapy-naive patients with advancedstage non-small-cell lung cancer," Journal of Clinical Oncology, vol. 26, no. 21, pp. 3543-3551, 2008.

[41] L. Kelland, "The resurgence of platinum-based cancer chemotherapy," Nature Reviews Cancer, vol. 7, no. 8, pp. 573-584, 2007.

[42] N. Nishiyama, S. Okazaki, H. Cabral et al., "Novel cisplatinincorporated polymeric micelles can eradicate solid tumors in mice," Cancer Research, vol. 63, no. 24, pp. 8977-8983, 2003.

[43] H. S. Oberoi, N. V. Nukolova, A. V. Kabanov, and T. K. Bronich, "Nanocarriers for delivery of platinum anticancer drugs," Advanced Drug Delivery Reviews, vol. 65, no. 13-14, pp. 1667-1685, 2013.

[44] H. Maeda, H. Nakamura, and J. Fang, "The EPR effect for macromolecular drug delivery to solid tumors: improvement of tumor uptake, lowering of systemic toxicity, and distinct tumor imaging in vivo," Advanced Drug Delivery Reviews, vol. 65, no. 1, pp. 71-79, 2013.

[45] K. J. Haxton and H. M. Burt, "Polymeric drug delivery of platinum-based anticancer agents," Journal of Pharmaceutical Sciences, vol. 98, no. 7, pp. 2299-2316, 2009.

[46] K. Cheng, S. Peng, C. Xu, and S. Sun, "Porous hollow $\mathrm{Fe}_{3} \mathrm{O}_{4}$ nanoparticles for targeted delivery and controlled release of cisplatin," Journal of the American Chemical Society, vol. 131, no. 30, pp. 10637-10644, 2009.

[47] N. Pothayee, N. Pothayee, N. Hu et al., "Manganese graft ionomer complexes (MaGICs) for dual imaging and chemotherapy," Journal of Materials Chemistry B, vol. 2, no. 8, pp. 1087-1099, 2014.

[48] R. Duncan, "Polymer conjugates as anticancer nanomedicines," Nature Reviews Cancer, vol. 6, no. 9, pp. 688-701, 2006.

[49] Q. Yin, J. Shen, Z. Zhang, H. Yu, and Y. Li, "Reversal of multidrug resistance by stimuli-responsive drug delivery systems for therapy of tumor," Advanced Drug Delivery Reviews, vol. 65, no. 13-14, pp. 1699-1715, 2013.

[50] Y. D. Livney and Y. G. Assaraf, "Rationally designed nanovehicles to overcome cancer chemoresistance," Advanced Drug Delivery Reviews, vol. 65, no. 13-14, pp. 1716-1730, 2013.

[51] A. M. Master, P. N. Williams, N. Pothayee et al., "Remote actuation of magnetic nanoparticles for cancer cell selective treatment through cytoskeletal disruption," Scientific Reports, vol. 6, no. 1, p. 33560, 2016.

[52] B. Kozissnik, A. C. Bohorquez, J. Dobson, and C. Rinaldi, "Magnetic fluid hyperthermia: advances, challenges, and opportunity," International Journal of Hyperthermia, vol. 29, no. 8, pp. 706-714, 2013.

[53] A. Jordan, R. Scholz, P. Wust, H. Fähling, and R. Felix, "Magnetic fluid hyperthermia (MFH): cancer treatment with AC magnetic field induced excitation of biocompatible superparamagnetic nanoparticles," Journal of Magnetism and Magnetic Materials, vol. 201, no. 1-3, pp. 413-419, 1999.

[54] B.-K. Jung, Y. K. Lee, J. Hong, H. Ghandehari, and C.-O. Yun, "Mild hyperthermia induced by gold nanorod-mediated plasmonic photothermal therapy enhances transduction and replication of oncolytic adenoviral gene delivery," ACS Nano, vol. 10, no. 11, pp. 10533-10543, 2016.

[55] K. H. Bae, M. Park, M. J. Do et al., "Chitosan oligosaccharidestabilized ferrimagnetic iron oxide nanocubes for magnetically modulated cancer hyperthermia," ACS Nano, vol. 6, no. 6, pp. 5266-5273, 2012.

[56] Z. S. Al-Ahmady, W. T. Al-Jamal, J. V. Bossche et al., "Lipidpeptide vesicle nanoscale hybrids for triggered drug release by mild hyperthermia in vitro and in vivo," ACS Nano, vol. 6, no. 10, pp. 9335-9346, 2012.

[57] B. P. Shah, N. Pasquale, G. de, T. Tan, J. Ma, and K. B. Lee, "Core-shell nanoparticle-based peptide therapeutics and combined hyperthermia for enhanced cancer cell apoptosis," ACS Nano, vol. 8, no. 9, pp. 9379-9387, 2014.

[58] A. K. Gupta and M. Gupta, "Synthesis and surface engineering of iron oxide nanoparticles for biomedical applications," Biomaterials, vol. 26, no. 18, pp. 3995-4021, 2005.

[59] T. Neuberger, B. Schöpf, H. Hofmann, M. Hofmann, and B. von Rechenberg, "Superparamagnetic nanoparticles for biomedical applications: possibilities and limitations of a new drug delivery system," Journal of Magnetism and Magnetic Materials, vol. 293, no. 1, pp. 483-496, 2005.

[60] A. E. Deatsch and B. A. Evans, "Heating efficiency in magnetic nanoparticle hyperthermia," Journal of Magnetism and Magnetic Materials, vol. 354, pp. 163-172, 2014.

[61] K. Maier-Hauff, R. Rothe, R. Scholz et al., "Intracranial thermotherapy using magnetic nanoparticles combined with external beam radiotherapy: results of a feasibility study on patients with glioblastoma multiforme," Journal of NeuroOncology, vol. 81, no. 1, pp. 53-60, 2007.

[62] K. Kakinuma, R. Tanaka, H. Takahashi, M. Watanabe, T. Nakagawa, and M. Kuroki, "Targeting chemotherapy for malignant brain tumor using thermosensitive liposome and localized hyperthermia," Journal of Neurosurgery, vol. 84, no. 2, pp. 180-184, 1996.

[63] R. D. Issels, "Hyperthermia adds to chemotherapy," European Journal of Cancer, vol. 44, no. 17, pp. 2546-2554, 2008.

[64] L.-Y. Zhang, H.-C. Gu, and X.-M. Wang, "Magnetite ferrofluid with high specific absorption rate for application in hyperthermia," Journal of Magnetism and Magnetic Materials, vol. 311, no. 1, pp. 228-233, 2007.

[65] A. Ito, K. Tanaka, H. Honda, S. Abe, H. Yamaguchi, and T. Kobayashi, "Complete regression of mouse mammary carcinoma with a size greater than $15 \mathrm{~mm}$ by frequent repeated hyperthermia using magnetite nanoparticles," Journal of Bioscience and Bioengineering, vol. 96, no. 4, pp. 364-369, 2003. 
[66] J.-P. Fortin, C. Wilhelm, J. Servais, C. Ménager, J. C. Bacri, and F. Gazeau, "Size-sorted anionic iron oxide nanomagnets as colloidal mediators for magnetic hyperthermia," Journal of the American Chemical Society, vol. 129, no. 9, pp. 26282635, 2007.

[67] A. Jordan, R. Scholz, P. Wust et al., "Effects of magnetic fluid hyperthermia (MFH) on $\mathrm{C} 3 \mathrm{H}$ mammary carcinoma in vivo," International Journal of Hyperthermia, vol. 13, no. 6, pp. 587-605, 1997.

[68] I. Gitsov and F. E. Johnson, "Synthesis and hydrolytic stability of poly(oxyethylene-H-phosphonate)s," Journal of Polymer Science Part A: Polymer Chemistry, vol. 46, no. 12, pp. 41304139, 2008.

[69] X. Xu, H. Yu, S. Gao, H. Q. Mao, K. W. Leong, and S. Wang, "Polyphosphoester microspheres for sustained release of biologically active nerve growth factor," Biomaterials, vol. 23, no. 17, pp. 3765-3772, 2002.

[70] L. Sandiford, A. Phinikaridou, A. Protti et al., "Bisphosphonate-anchored PEGylation and radiolabeling of superparamagnetic iron oxide: long-circulating nanoparticles for in vivo multimodal (T1 MRI-SPECT) imaging," ACS Nano, vol. 7, no. 1, pp. 500-512, 2013.

[71] D. Portet, B. Denizot, E. Rump, J.-J. Lejeune, and P. Jallet, "Nonpolymeric coatings of iron oxide colloids for biological use as magnetic resonance imaging contrast agents," Journal of Colloid and Interface Science, vol. 238, no. 1, pp. 37-42, 2001.

[72] S. Mohapatra, S. K. Mallick, T. K. Maiti, S. K. Ghosh, and P. Pramanik, "Synthesis of highly stable folic acid conjugated magnetite nanoparticles for targeting cancer cells," Nanotechnology, vol. 18, no. 38, article 385102, 2007.

[73] N. Pothayee, S. Balasubramaniam, R. M. Davis et al., "Synthesis of 'ready-to-adsorb' polymeric nanoshells for magnetic iron oxide nanoparticles via atom transfer radical polymerization," Polymer, vol. 52, no. 6, pp. 1356-1366, 2011.

[74] C. S. Brazel, "Magnetothermally-responsive nanomaterials: combining magnetic nanostructures and thermally-sensitive polymers for triggered drug release," Pharmaceutical Research, vol. 26, no. 3, pp. 644-656, 2009.

[75] P. M. Peiris, A. Abramowski, J. Mcginnity et al., "Treatment of invasive brain tumors using a chain-like nanoparticle," Cancer Research, vol. 75, no. 7, pp. 1356-1365, 2015.

[76] N. Hu, L. M. Johnson, N. Pothayee et al., "Synthesis of ammonium bisphosphonate monomers and polymers," Polymer, vol. 54, no. 13, pp. 3188-3197, 2013.

[77] J. Park, K. An, Y. Hwang et al., "Ultra-large-scale syntheses of monodisperse nanocrystals," Nature Materials, vol. 3, no. 12, pp. 891-895, 2004.

[78] K. Davis, B. Cole, M. Ghelardini, B. A. Powell, and O. T. Mefford, "Quantitative measurement of ligand exchange with small-molecule ligands on iron oxide nanoparticles via radioanalytical techniques," Langmuir, vol. 32, no. 51, pp. 13716-13727, 2016.

[79] K. Davis, B. Qi, M. Witmer, C. L. Kitchens, B. A. Powell, and O. T. Mefford, "Quantitative measurement of ligand exchange on iron oxides via radiolabeled oleic acid," Langmuir, vol. 30, no. 36, pp. 10918-10925, 2014.

[80] J. D. Goff, P. P. Huffstetler, W. C. Miles et al., "Novel phosphonate-functional poly(ethylene oxide)-magnetite nanoparticles form stable colloidal dispersions in phosphatebuffered saline," Chemistry of Materials, vol. 21, no. 20, pp. 4784-4795, 2009.
[81] S. Balasubramaniam, N. Pothayee, Y. Lin et al., "Poly(Nisopropylacrylamide)-coated superparamagnetic iron oxide nanoparticles: relaxometric and fluorescence behavior correlate to temperature-dependent aggregation," Chemistry of Materials, vol. 23, no. 14, pp. 3348-3356, 2011.

[82] T. Boulikas and M. Vougiouka, "Recent clinical trials using cisplatin, carboplatin and their combination chemotherapy drugs (review)," Oncology Reports, vol. 11, no. 3, pp. 559595, 2004.

[83] V. Pinzani, F. Bressolle, I. J. Haug, M. Galtier, J. P. Blayac, and P. Balmès, "Cisplatin-induced renal toxicity and toxicitymodulating strategies: a review," Cancer Chemotherapy and Pharmacology, vol. 35, no. 1, pp. 1-9, 1994.

[84] N. Hu, "Block and graft copolymers containing carboxylate or phosphonate anions," in Department of Chemistry, $E d$., Virginia Polytechnic Institute and State University, 2014.

[85] S. Narayanan, B. N. Sathy, U. Mony, M. Koyakutty, S. V. Nair, and D. Menon, "Biocompatible magnetite/gold nanohybrid contrast agents via green chemistry for MRI and CT bioimaging," ACS Applied Materials \& Interfaces, vol. 4, no. 1, pp. 251-260, 2012.

[86] L. Xiao, J. Li, D. F. Brougham et al., "Water-soluble superparamagnetic magnetite nanoparticles with biocompatible coating for enhanced magnetic resonance imaging," ACS Nano, vol. 5, no. 8, pp. 6315-6324, 2011.

[87] C. Sun, J. S. H. Lee, and M. Zhang, "Magnetic nanoparticles in MR imaging and drug delivery," Advanced Drug Delivery Reviews, vol. 60, no. 11, pp. 1252-1265, 2008.

[88] Z. R. Stephen, F. M. Kievit, and M. Zhang, "Magnetite nanoparticles for medical MR imaging," Materials Today, vol. 14, no. 7-8, pp. 330-338, 2011.

[89] Y.-w. Jun, J.-H. Lee, and J. Cheon, "Chemical design of nanoparticle probes for high-performance magnetic resonance imaging," Angewandte Chemie International Edition, vol. 47, no. 28, pp. 5122-5135, 2008.

[90] M. Rohrer, H. Bauer, J. Mintorovitch, M. Requardt, and H. J. Weinmann, "Comparison of magnetic properties of MRI contrast media solutions at different magnetic field strengths," Investigative Radiology, vol. 40, no. 11, pp. 715-724, 2005.

[91] C. Wu, Y. Xu, L. Yang et al., "Negatively charged magnetite nanoparticle clusters as efficient MRI probes for dendritic cell labeling and in vivo tracking," Advanced Functional Materials, vol. 25, no. 23, pp. 3581-3591, 2015.

[92] X. Cui, M. A. Green, P. J. Blower et al., “ $\mathrm{Al}(\mathrm{OH})_{3}$ facilitated synthesis of water-soluble, magnetic, radiolabelled and fluorescent hydroxyapatite nanoparticles," Chemical Communications, vol. 51, no. 45, pp. 9332-9335, 2015.

[93] M. José Sánchez-Moreno, R. B. Gómez-Coca, A. FernándezBotello et al., "Synthesis and acid-base properties of $(1 \mathrm{H}-$ benzimidazol-2-yl-methyl)phosphonate (Bimp2-). Evidence for intramolecular hydrogen-bond formation in aqueous solution between (N-1)H and the phosphonate group," Organic \& Biomolecular Chemistry, vol. 1, no. 10, pp. 18191826, 2003.

[94] M. Ma, Y. Wu, J. Zhou, Y. Sun, Y. Zhang, and N. Gu, "Size dependence of specific power absorption of $\mathrm{Fe}_{3} \mathrm{O}_{4}$ particles in AC magnetic field," Journal of Magnetism and Magnetic Materials, vol. 268, no. 1-2, pp. 33-39, 2004. 
[95] M. S. A. Darwish, A. El-Sabbagh, and I. Stibor, "Hyperthermia properties of magnetic polyethylenimine core/shell nanoparticles: influence of carrier and magnetic field strength," Journal of Polymer Research, vol. 22, no. 12, p. 239, 2015.

[96] E. C. Vreeland, J. Watt, G. B. Schober et al., "Enhanced nanoparticle size control by extending LaMer's mechanism," Chemistry of Materials, vol. 27, no. 17, pp. 6059-6066, 2015. 


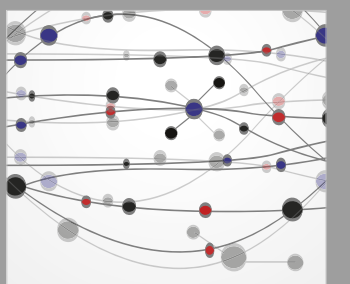

The Scientific World Journal
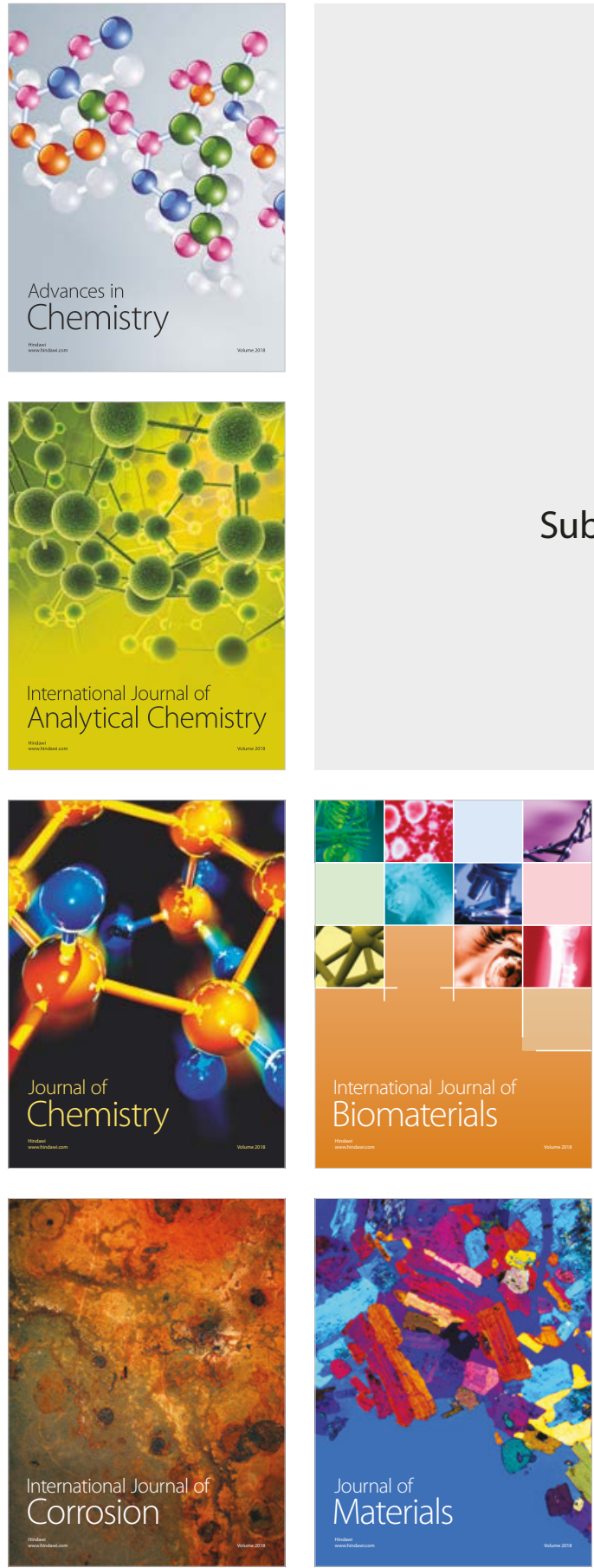

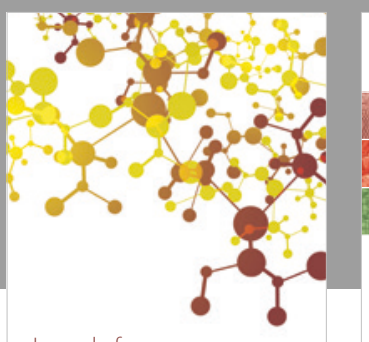

Journal of

Applied Chemistry
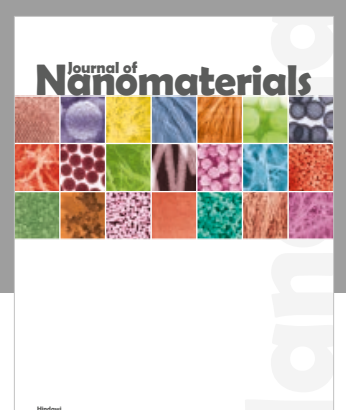

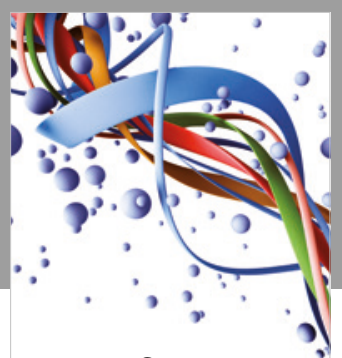

Scientifica

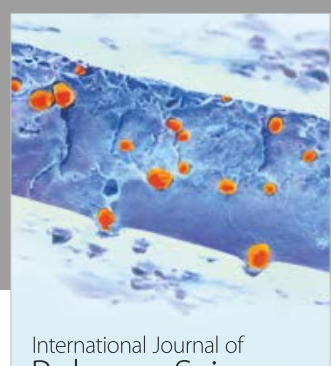

Polymer Science

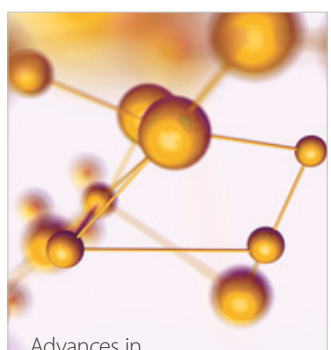

Physical Chemistry
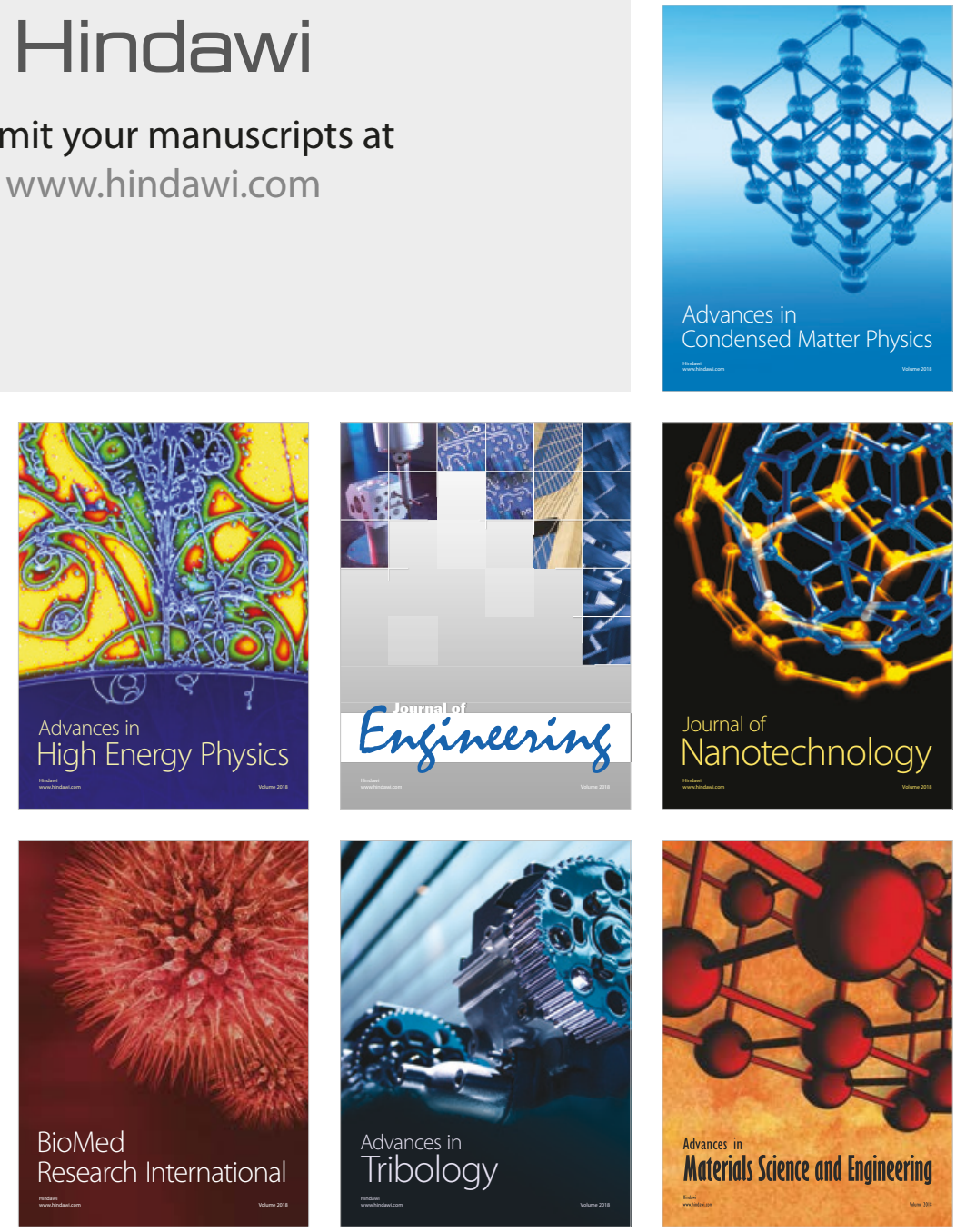